\title{
O MÍNIMO EXISTENCIAL, LIBERDADE E JUSTIÇA SOCIAL
}

\author{
Simone Loncarovich Bussi* \\ Teófilo Marcelo de Arêa Leão Junior ${ }^{* *}$ \\ Julia Thais de Assis Moraes**
}

\section{RESUMO}

A garantia do mínimo existencial, como direito fundamental quando não positivados ao texto constitucional, traz alguns enfrentamentos ao poder público tendo em vista, a necessidade de viabilizá-los ao longo do tempo para que o ser humano tenha uma vida digna que acompanhe a evolução da sociedade. O presente artigo discute o conceito, a origem e a amplitude do direito ao mínimo existencial, tendo em vista o fundamento da dignidade da pessoa humana e a realização da efetiva justiça social. Assim, a pesquisa analisará de maneira explicativa o tema, utilizando-se do método dedutivo com exploração bibliográfica.

Palavras-chave: mínimo existencial. direitos fundamentais sociais. Liberdade. justiça social. Dignidade da pessoa humana.

\section{THE EXISTENTIAL MINIMUM, FREEDOM AND SOCIAL JUSTICE}

\begin{abstract}
The guarantee of the existential minimum, as a fundamental right when not made positive by the constitutional text, brings some confrontations to the public power in view, the need to make them viable over time so that the human being has a dignified life that accompanies the evolution of society. This article discusses the concept, origin and breadth of the right to the existential minimum, in view of the foundation of human dignity and the realization of effective social justice. Thus, the research will analyze the theme in an explanatory manner, using the deductive method with bibliographic exploration.
\end{abstract}

\footnotetext{
* Mestranda em Teoria Geral do Direito pelo Centro Universitário de Marília UNIVEM (2019/2021), Graduada em direito pelo Centro Universitário Católico Salesiano Auxilium - SP (2014/2018). Advogada. email: simonebussi@hotmail.com. Endereço: Rua Aguapeí, 3300, Jardim do Prado, Araçatuba-SP. CEP: 16025-455.

** Pós-doutor em Direito pelo Ius Gentium Conimbrigae da Faculdade de Direito da Universidade de Coimbra (2015). Doutor em Direito pela Instituição Toledo de Ensino - ITE, Bauru-SP (2012). Mestre em Direito das Relações Sociais pela Pontifícia Universidade Católica de São Paulo, PUC-SP (2001). Graduado pela Faculdade de Direito de Marília, hoje Curso de Direito do Centro Universitário Eurípides de Marília, UNIVEM, mantida pela Fundação Eurípides Soares da Rocha (1995). Líder do Grupo de Pesquisa: Direitos Fundamentais Sociais, DIFUSO. Autor de obras e artigos científicos. Professor da Graduação (1999), Mestrado (2012) do UNIVEM e Advogado (1996), e-mail teofilo@arealeao.com, Endereço postal: Rua Sílvio Marinho n. 177, Jardim Tangará, Marília-SP CEP 17516-020.

*** Mestranda em Teoria Geral do Direito pelo Centro Universitário de Marília UNIVEM 2019/2021 em Ciências Sociais 2019/2021 pela Universidade Estadual Paulista (UNESP), no Campus de Marília - FFC. Graduada em Direito (2014/2018) na Universidade Federal de Mato Grosso do Sul/ UFMS-CPTL, e-mail: juliamoraes094@outlook.com. Endereço Postal : Avenida 9 de Julho 103, Centro, Valparaíso/ SP ,CEP : 16880000 .
} 
Key words: minimum existential. fundamental social rights. Freedom. social justice. Dignity of human person.

\section{Introdução}

No decorrer do tempo, o avanço dos direitos sociais contribuiu para que sobressaíssem garantias ao direito às condições mínimas de existência do indivíduo, de modo que, seus destinatários pudessem plenamente usufruir não somente do exercício dos direitos sociais, mas também, dos direitos civis e políticos.

Todavia, com a evolução da sociedade, nítidas são as mudanças na maneira como se interpreta e, se entende as relações entre o Estado e o indivíduo no decorrer do tempo. Os direitos foram e continuam sendo conquistados por um enfrentamento gradual do homem na sociedade em defesa de novas liberdades.

Ao longo dessa evolução social e da formação dos diferentes tipos de Estado Liberal, Social e Democrático, pode-se compreender que a existência de lutas sociais e políticas demarcaram uma evolução no pensamento e na compreensão da sociedade e do Estado do quanto é importante a proteção e a garantia dos direitos fundamentais, além da democracia e da cidadania.

No Estado Democrático de Direito, o movimento do cidadão é no sentido de atuar como sujeito ativo do processo de evolução social, na busca de maior igualdade social com maior segurança jurídica. Percebe-se, então que, as mudanças no Estado e na sociedade simbolizam a singularidade do ser humano, que busca agir orientado a um fim de acordo com as contingências históricas e as necessidades sociais existentes.

Como forma de equilibrar as desigualdades sociais e o desenvolvimento humano, o Estado deve ser instigado a realizar o movimento de ponderar entre essas desigualdades e os poderes necessários para garantir ao indivíduo uma vida digna.

Contudo, diante de várias necessidades humanas e dos recursos financeiros escassos, o Estado tem apontado frequentemente o direito à reserva do possível, como argumento de aceitação para a inércia do poder público frente às mazelas sociais. Mas, o argumento do mínimo existencial também, vem sendo apontado pelos juristas e doutrinadores como ferramenta de nivelamento das desigualdades sociais frente a inércia do 
Estado

Nesse sentido, verifica-se que a teoria do mínimo existencial objetiva diferenciar quais são os direitos sociais mínimos destinados a garantir a subsistência das pessoas e o exercício de suas liberdades onde, atualmente, no contexto brasileiro, o judiciário surge como uma alternativa de cumprimento das expectativas sociais contemporâneas diante da estagnação do executivo e do legislativo.

Os direitos sociais mínimos não deveriam ser subordinados à reserva do possível por possuírem prioridade em sua efetivação já que, garantem a dignidade da pessoa humana. Porém, verifica-se que a realização fática dos direitos sociais mínimos tem apresentado controvérsias doutrinárias e, também, dificuldades materiais para sua realização.

Assim, o desafio para o alcance desse direito é encontrar equilíbrio nas ações públicas para que ocorra a realização fática dos direitos sociais mínimos diante da escassez de recursos públicos e, da priorização de determinados direitos, em uma determinada época e sociedade. São pontos que geram conflitos entre os poderes Judiciário, Legislativo e Executivo, quanto ao conteúdo, a eficácia e a efetividade do direito ao mínimo existencial necessário a sociedade.

Nesse sentido, levar-se-á em consideração a perspectiva histórica da origem da teoria do mínimo, pois não há nenhuma sociedade atual que não seja marcada por lutas e desafios pretéritos. É nesse contexto de evolução dos direitos fundamentais sociais estabelecidos na Constituição Federal do Brasil de 1988, que se faz necessário discutir a origem, a amplitude do conceito, os fundamentos, os sujeitos envolvidos para a efetivação do direito ao mínimo existencial e o alcance da justiça social. Assim, a pesquisa analisará de maneira explicativa o tema, utilizando-se do método dedutivo com exploração bibliográfica.

\section{A origem da teoria do mínimo existencial}

Observa-se nos registros bibliográficos que tanto a teoria do mínimo existencial quanto a teoria da reserva do possível tiveram como berço o direito alemão. Robert Alexy (2008) aponta que a justificativa, dessa origem ser na Alemanha, é devido à ausência de previsão constitucional expressa sobre direitos sociais prestacionais embora tenha havido proteção ainda que cautelosa e tímida em situações específicas como a maternidade, o casamento e a família (ESPINOZA, 2017). 
Ainda que não houvesse previsão expressa sobre os direitos sociais típicos de cunho prestacional no texto alemão, a discussão sobre a garantia do mínimo existencial ganhou destaque na doutrina e na jurisprudência, tendo em vista ser um direito fundamental que assegura condições materiais mínimas para uma vida com dignidade (SARLET; ZOCKUN, 2016).

Um dos primeiros documentos destacados que denota a observação a garantia ao mínimo existencial é a Legislação da Prússia, que previa a obrigação do Estado em garantir alimentos aos cidadãos desamparados, datada no século XVI em 1795. A Speedhamland Law (Poor Laws inglesas) de 1795 indicava que deveria haver assistência social aos desamparados suprimindo assim, o trabalho obrigatório (PEREIRA, 2000).

A Revolução Francesa, no início do constitucionalismo moderno, assumiu certa importância na discussão do reconhecimento ao direito à subsistência com os chamados “direitos do homem pobre”, indicando um direito ao mínimo existencial. Neste período buscava-se romper com a ideia de caridade, refutando assim, o pensamento do filósofo inglês Herbert Spencer sobre o darwinismo social (SARLET; ZOCKUM, 2016).

No darwinismo social de Spencer qualquer proteção do Estado ou da sociedade aos vulneráveis deveria ser repelida pois, nesse pensamento somente os mais aptos deveriam sobreviver. Este rompimento com o darwinismo social trouxe a inserção, ainda que simbólica, no texto da Constituição Francesa de 1793 do direito aos necessitados aos socorros públicos (SARLET; ZOCKUM. 2016).

Nessa busca pela evolução da proteção da dignidade da pessoa humana, através do reconhecimento de um direito a prestações matériais por parte do Estado, pode ser destacado o texto Constituição da República de Weimar da Alemanha, que em 1919, em seu artigo 151 dispunha que a vida econômica deve corresponder aos ditames da justiça e tem como objetivo assegurar a todos uma existência com dignidade (SARLET; ZOCKUN, 2016).

No plano internacional em 1948, pode ser salientado o artigo XXV da Declaração da ONU que atribuiu a todas as pessoas o direito ao mínimo existencial, ou seja, o direito a um nível de vida suficiente para assegurar a sua saúde, o seu bem-estar e o de sua família, prevendo, assim, a proteção ao mínimo existencial tendo em vista o princípio da dignidade da pessoa humana. A partir dessa perspectiva em que se impunha a necessidade de se observar a proteção ao mínimo existencial em 1949, ainda que a Lei Fundamental alemã não tivesse positivado expressamente os direitos sociais típicos de cunho prestacional, atentou-se 
por proteger expressamente direitos relativos à maternidade, aos filhos, as mulheres e aos portadores de deficiência onde, o Estado deveria atuar positivamente para compensar desigualdades fáticas referentes à discriminação.

No plano doutrinário, no início da década de 1950 (no segundo Pós-Guerra), destaca-se Otto Bachof, que sustentou a possibilidade de um direito subjetivo à garantia positiva de recursos mínimos para uma existência digna, direito este do Estado Social e, decorrente do princípio da dignidade da pessoa humana, do direito à vida e à liberdade. Bachof entendia que a dignidade da pessoa humana não reclamaria apenas a garantia da liberdade, mas também um mínimo de segurança social, já que sem tais recursos, a própria dignidade humana restaria comprometida. Ou seja, “[...] o direito à vida, ou à vida digna, não postula somente a garantia de liberdade, mas necessita também de posições ativas indispensáveis à sua promoção" (BITENCOURT NETO, 2010, p. 54-55).

Um ano após a publicação de Otto Bachof sobre a necessidade de o Estado observar não somente as esferas de liberdade do indivíduo, mas também as condições materiais para que este tenha uma vida digna, o Tribunal Federal Administrativo da Alemanha (Bundesverwaltungsgericht), reconheceu o direito subjetivo do indivíduo carente ao auxílio material por parte do Estado, fundado na conjugação da dignidade da pessoa humana, da cláusula do Estado Social e dos direitos à liberdade e à vida (SARLET, 2007). Direito este que foi regulado pelo legislador, em nível infraconstitucional com a Lei de Assistência Social (Bundessozialhilfegesetz) em seu inciso I, do artigo 4º (SARLET; ZOCKUM, 2016).

O Tribunal Constitucional Federal Alemão em 1954 na decisão BVerfGE firma acórdão no mesmo sentido de entendimento do Tribunal Administrativo. O recurso ora analisado foi contra a decisão proferida pelo Tribunal Estadual Alemão que considerou inconstitucional o dispositivo vigente na época sobre a legislação previdenciária. Nessa questão previdenciária foi analisada possiblidade de estender, a idade máxima de pensão por morte de 25 anos, para órfãos portadores de deficiência (ESPINOZA, 2017). No entanto, o Tribunal Estadual Alemão entendeu que o limite etário de 25 anos determinado aos órfãos, não deveria prevalecer para os órfãos com alguma deficiência física ou metal já que estes não conseguiriam manter sua própria subsistência. A decisão da Corte Federal Constitucional essencialmente reconheceu em definitivo o status constitucional do direito ao mínimo existencial, mas, manteve o limite etário de 25 anos aos órfãos deficientes físicos ou mental evitando, desse modo atuar em nome do poder legislativo a fim de que o processo democrático 
seja preservado, embora tenha determinado prazo para o legislativo corrigir o limite etário (ESPINOZA, 2017).

Nessa importante decisão, a Corte alemã assentou:

Certamente a assistência aos desamparados integra as obrigações de um Estado Social (...). Isto inclui, necessariamente, a assistência social aos concidadãos, que, em virtude de sua precária condição física e mental, se encontram limitados nas suas atividades sociais, não apresentando condições de prover a própria subsistência. A comunidade estatal deve assegurar-lhes pelo menos as condições mínimas para uma existência digna e envidar os esforços necessários para integrar estas pessoas na comunidade, fomentando o seu acompanhamento e apoio na família ou por terceiros, bem como criando as indispensáveis instituições assistenciais (SARLET, 2015, p.3).

A Corte Alemã destaca o papel do Estado Social na proteção dos vulneráveis, provendo as condições mínimas para uma existência humana digna. Todavia, impõe a observação do princípio da separação dos poderes em um Estado Democrático de Direito. Sarlet e Zockun (2016) destacam que o direito à assistência social na Alemanha integra o conteúdo do princípio do Estado Social de Direito , sendo a principal manifestação da garantia do mínimo existencial, alcançando o caráter de uma ajuda para a autoajuda (Hilfe zur Selbsthilfe), não tendo por objeto especificamente somente o estabelecimento da dignidade em si mesma, mas sua proteção e promoção. Há que destacar que:

[...] o indivíduo deve poder levar uma vida que corresponda com as exigências do princípio da dignidade da pessoa humana, razão pela qual o direito à assistência social - considerado, pelo menos na Alemanha e, de modo geral, nos países que integram a União Europeia, a principal manifestação da garantia do mínimo existencial - alcança o caráter de uma ajuda para a auto-ajuda (Hilfe zur Selbsthilfe), não tendo por objeto o estabelecimento da dignidade em si mesma, mas a sua proteção e promoção (SARLET; ZOCKUM, 2016, p. 121).

Desde então, várias interpretações sobre o mínimo existencial têm sido apontadas com variações no conceito ou com concepções parecidas em diversos países, como: Portugal, Índia, Israel e Colômbia (SARMENTO, 2019).

No Brasil, Daniel Sarmento (2019, p. 190-191) destaca a importante contribuição em 1933 do jurista brasileiro Pontes de Miranda com a obra "Os novos direitos do homem”. Nessa importante contribuição, o jurista indica a necessidade de o Estado observar a existência de um direito público à subsistência, que compreende "os cinco direitos do homem", ou seja, direito à subsistência, ao trabalho, educação, à assistência e o direito ao “ideal”. Estes direitos do homem, destacados pelo autor, devem ser prestados pelo Estado, não devendo o indivíduo receber de mais ninguém quando lhe falte pois, não deve faltar ao 
ser humano o que for indispensável à sua vida (mínimo vital absoluto) e o que for indispensável às condições relativas ao tempo, lugar para cada sociedade (mínimo vital relativo).

\begin{abstract}
Como direito público subjetivo, a subsistência realiza, no terreno da alimentação, das vestes e da habitação, o standard of living segundo três números, variáveis para maior indefinidamente e para menor até o limite, limite que é dado, respectivamente, pelo indispensável à vida quanto à nutrição, ao resguardo do corpo e à instalação. É o mínimo vital absoluto. Sempre, porém, que nos referirmos ao mínimo vital, deve-se entender o mínimo vital relativo, aquele que, atentando-se às circunstâncias de lugar e de tempo, se fixou para cada zona em determinado período [...]. O mínimo vital relativo tem de ser igual ou maior que o absoluto. O direito à subsistência torna sem razão de ser a caridade, a esmola, a humilhação do homem ante o homem. [...]. Não se peça a outrem, porque falte; exija-se do Estado, porque este deve. Em vez da súplica, o direito (PONTES DE MIRANDA, 1933, p. 28-30 apud SARMENTO, 2019, p. 191).
\end{abstract}

No Brasil, embora o texto constitucional expresse normas fundamentais sociais, o Supremo Tribunal Federal em 2004, teve um papel de destaque, em célebre decisão (ADPF $45,29.04 .2004)$ ao acolher o direito ao mínimo existencial conforme já vinha a doutrina brasileira apontando. Contudo, na leitura de Daniel Sarmento (2019, p. 194) o acolhimento jurisprudencial e doutrinário ao mínimo existencial no Brasil, tem sido utilizado de modo retórico e sem limite definido porque não atinge porções significativas da população brasileira.

[...] parcelas expressivas da população brasileira, que não desfrutam de acesso efetivo a bens e direitos essenciais para uma vida digna. Legiões de pessoas ainda vivem na mais absoluta miséria, expostas à insegurança alimentar, sem acesso à moradia adequada, ao saneamento básico, à saúde e à educação de mínima qualidade. À margem das conquistas civilizatórias do Estado democrático de direito, ainda existe um "Brasil de baixo" - do qual nos falou Patativa do Assaré em que a regra é a privação, e onde os direitos não são "para valer". Além de acarretar injusto sofrimento às suas vítimas, esse quadro acaba também comprometendo a capacidade de tais pessoas de exercerem, de forma plena e consciente, os seus direitos civis e políticos (SARMENTO, 2019, p. 194).

Embora haja a garantia constitucional do mínimo existencial, a sua efetividade é insuficiente. No Brasil, grande parte da população sofre em condições indignas as realidades da vida, o que representa grande injustiça independentemente dos fundamentos jurídicos apontados como base ao quanto e como garantir o direito fundamental ao mínimo existencial. Assim, o próximo tópico delineará, mas não de modo aprofundado, sobre os fundamentos filosóficos para o mínimo existencial. 


\section{Fundamentos filosóficos para o mínimo existencial}

Ao longo do tempo, Daniel Sarmento (2019, p. 195) destaca que houve várias preocupações morais com os direitos ou bem-estar social devido a "sombra de medo" de que houvesse "movimentos sociais que pudessem abalar o status a quo" do Estado.

Vários são os argumentos a favor da proteção de direitos sociais mínimos a fim de que se alcance a proteção a dignidade da pessoa humana.

O mínimo existencial não possui delimitação contextual, nem previsão expressa no texto constitucional, podendo então, abranger qualquer direito, ainda que originariamente não-fundamental. No entanto, o direito ao mínimo deve ser considerado em sua dimensão como um direito essencial e inalienável" pois, deve estar ligado à ideia de justiça e de redistribuição de riqueza social. Ademais, o direito ao mínimo existencial, não é mensurável pela quantidade, mas sim pela qualidade, ou seja, pelo máximo de utilidade (Maximum welfare, Nutzenmximierung), o que torna difícil mensurá-lo principalmente, em sociedades periféricas com grandes desigualdades sociais (TORRES, 1989, p. 29)

Conquanto não possua delimitação o conceito, a extensão ou a forma de proteção desses direitos, ainda assim, há uma convergência doutrinária e jurisprudencial no sentido de garantir condições materiais básicas para uma vida digna, independentemente dos fundamentos apontados.

Os fundamentos para o reconhecimento do mínimo existencial de acordo com Daniel Sarmento podem ser instrumentais ou independentes. Os fundamentos instrumentais destacam que, o mínimo existencial deve ser assegurado para que, outros princípios como liberdade e democracia sejam promovidos e, os fundamentos independentes enfatizam que o mínimo existencial deve ser garantido independentemente de possuir efeitos sobre outros valores, argumento ao qual o autor se filia (SARMENTO, 2019).

Dentre os doutrinadores que se destacam pelo reconhecimento do mínimo existencial alicerçado em fundamentos instrumentais pode ser citado Robert Alexy (2008) que visualiza a teoria do mínimo existencial no argumento da liberdade, por meio da filosofia política e do diálogo que realiza entre a dogmática constitucional e a jurisprudência alemã. Nesse diálogo, indica que é possível verificar direitos fundamentais sociais implícitos no texto constitucional alemão com diferentes graus de vinculação. Os direitos fundamentais sociais implícitos por ele destacados podem ser normas objetivas, 
vinculantes apenas ao legislador; ou ser direitos subjetivos, exigíveis somente com atuação legislativa e, ainda ser direitos subjetivos definitivos vinculantes. Entendendo-se este último como direito à moradia, à saúde, à educação escolar e à formação profissional, que a prima facie possuem grau máximo de vinculação.

Independentemente da positivação dos direitos fundamentais sociais, o indivíduo somente poderá exercer suas liberdades jurídicas se, forem garantidas suas liberdades fáticas pois, “[...] bens materiais básicos seriam, assim, pressupostos para a autodeterminação social" (ESPINOZA, 2017, p. 104-105). Ademais, é necessário que as pessoas tenham condições mínimas de sobrevivência para que haja a real proteção ao princípio da dignidade da pessoa humana associado ao desenvolvimento livre e a liberdade de atuar (ESPINOZA, 2017, p. 105).

Nesse sentido, destaca Fernando Facury Scaff (2006, p. 38) sobre a importância do reconhecimento do direito ao mínimo existencial nos "países que se encontram na periferia do capitalismo" como forma de proteção ao livre desenvolvimento humano.

[..] é imperioso notar que o conceito de mínimo existencial, ancorado no primado da liberdade, deve possuir maior amplitude naqueles países que se encontram na periferia do capitalismo. Afinal, só pode exercer com plenitude a liberdade, mesmo no âmbito do mínimo existencial, "quem possui capacidade para exercê-la. E para que seja possível esse exercício de liberdade jurídica é necessário assegurar a liberdade real" (Alexy), "ou a possibilidade de exercer suas capacidades" (Amartya), através dos direitos fundamentais sociais (SCAFF, 2006, p.38).

Ainda, Scaff (2006, p. 38) destaca que em uma sociedade economicamente desigual, é mais difícil que os direitos fundamentais sociais sejam assegurados a todos pelo Estado, tendo-se em vista que a liberdade jurídica somente é assegurada àqueles que conseguem exercer a liberdade fática (Alexy) ou àqueles que possuam liberdade para escolher dentre vários estilos de vida (capacidades ou condições - para fazê-lo, segundo Amartya Sem). Nesse sentido, faz-se necessário a garantia do mínimo existencial a todos para que assim sejam concretizadas as liberdades jurídicas (SCAFF, 2006).

Para assegurar o "mínimo existencial" no âmbito positivo (status positivus libertatis), é imperioso garantir o status de direito fundamental aos direitos sociais. Sem isso, os direitos fundamentais serão letra morta, pois se configurarão em liberdades jurídicas, sem possibilidade fática de exercício por grande parte da sociedade. Grande parte da população será parcialmente excluída da comunidade jurídica, pois não poderá exercer seus direitos, mas será compelida a cumprir seus deveres para com o Estado e as demais parcelas da sociedade (SCAFF, 2006, p. $38)$. 
Em países como o Brasil, por exemplo, com grandes desigualdades econômicas e sociais pode-se verificar que, atribuir ao direito social o valor de direito fundamental faz-se necessária, a fim de conseguir nivelar as desigualdades existentes. Todavia, observa-se que em países periféricos, com desnivelamento de possibilidades, as liberdades jurídicas são comprometidas pela ausência de garantia do Estado das liberdades fáticas. Assim, de acordo com Robert Alexy (2008), ao vincular direitos sociais à direitos fundamentais sob o aspecto da liberdade, deve-se levar em consideração que, ao indivíduo é necessário que seja assegurado não viver abaixo do mínimo existencial, pois, não deve o indivíduo ser/estar excluído da vida social de seu tempo e da sua sociedade.

Os direitos fundamentais sociais quando assegurados, para que a pessoa se desenvolva livremente, têm uma importância existencial para o indivíduo como ser formador de uma sociedade e, como pessoa respeitada dignamente pelo Estado.

Contudo, Robert Alexy (2008) destaca que garantir a liberdade fática enseja diversos problemas como: primeiro, o fato de haver conflito entre a proteção judicial e a competência do legislador para definir políticas públicas sociais e orçamentárias relacionadas aos direitos prestacionais; segundo, o reconhecimento de que a proteção aos direitos sociais tende a colidir com outros direitos e deveres, como por exemplo, a necessidade de aumento da carga tributária com o objetivo de financiar a garantia aos direitos prestacionais materiais, o que repercute sobre a propriedade privada.

Na busca para uma solução aos problemas a serem enfrentados, Robert Alexy (2008) sustenta que a efetivação dos direitos fundamentais sociais deve ser através do sopesamento entre os princípios, ponderando os princípios materiais e fundamentais envolvidos com o princípio da liberdade fática e o princípio da separação dos poderes. A teoria da ponderação na Alemanha, resulta no reconhecimento de um direito fundamental definitivo ao mínimo existencial (ALEXY, 2008).

[...] a questão acerca de quais direitos fundamentais sociais o indivíduo
definitivamente tem é uma questão de sopesamento entre princípios. De um lado
está sobretudo o princípio da liberdade fática. Do outro lado estão os princípios
formais, da liberdade decisória do legislador democraticamente legitimado e o
princípio da separação de poderes, além de princípios materiais, que dizem respeito
sobretudo à liberdade jurídica de terceiros, mas também a outros direitos
fundamentais sociais e interesses coletivos (ALEXY, 2008, p. 512).

No Brasil, conquanto haja no texto constitucional de 1988, um elenco extenso de direitos fundamentais sociais ainda, há muito que se desenvolver no contexto do mínimo 
existencial principalmente, quanto a utilização jurídica desse recurso na ausência de legislação específica ou na ausência de política públicas que promovam o exercício aos direitos fundamentais sociais mínimos.

Em 1989 o jurista brasileiro Ricardo Lobo Torres destaca na doutrina nacional o estudo do mínimo existencial para uma existência humana digna sob o pressuposto inicial da liberdade, da igualdade (proteção de pobreza absoluta), da dignidade da pessoa humana e a cláusula de Bem-Estar Social (TORRES, 2003). Dito de outro modo, "sem possibilidade de sobrevivência ou em estado de pobreza absoluta não existem condições de exercício da liberdade" (ESPINOZA, 2017, p. 105-107).

Torres indica que o mínimo existencial não se confunde com direitos sociais e econômicos, pois estes estão ligados à ideia de promoção da justiça social e que dependem de escolhas legislativas e das contingências econômicas. Assim, Torres (2003, p.15) fundamenta sua teoria com base em dois elementos: um com aspecto negativo de direito de defesa, configurando em um poder de autodeterminação do indivíduo que deve ser exercido sem o constrangimento do Estado (a título de exemplo: habeas data, gratuidade aos pobres na forma da lei de certidões de nascimento e de óbito, ente outros temas) e, outro com aspecto positivo que "postula a entrega de prestações de assistência social aos pobres, de auxílios financeiros de entidades filantrópicas e de bens públicos (roupas, remédios, alimentos etc.) à população carente".

Torres (2013) destaca que a pretensão a ser deduzida em juízo pelo cidadão deve ser a implementação de políticas públicas e não à entrega individual de bens públicos pois, as prestações positivas não se encontram à disposição dos poderes legislativo ou executivo e muito menos, se submetem à reserva do possível (ESPINOZA, 2017). Sendo, o mínimo existencial condição de liberdade,

[...] configura proteção do indivíduo contra ingerência indevida do legislador em ações e bens que possibilitem a sobrevivência digna (status negativus), bem como consiste no direito a prestações estatais básicas para o alcance dessa sobrevivência digna - status positivus libertatis - [...] (TORRES, 1989 apud ESPINOZA, 2017, p. 106).

Já o jurista brasileiro Sarlet (2012) compreende e destaca o mínimo existencial como um direito autônomo que, mesmo sem a atuação dos poderes executivo e legislativo pode ensejar a atuação do poder judiciário, justificando assim, a concessão judicial de determinadas prestações. Mesmo sem se confundir com direitos sociais, o mínimo 
existencial pode servir como parâmetro para interpretar o conteúdo e a eficácia dos direitos sociais (SARLET, 2012).

Em seu pensamento, o conteúdo do mínimo existencial não deve ser limitado tendo em vista, as mudanças sociais constantes. O mínimo existencial para Sarlet (2010, p. 346) são "todas as prestações indispensáveis à promoção, proteção e fruição de uma vida digna (que podem variar de acordo com as circunstâncias) necessariamente compõem o mínimo existencial”. Em aberto, o tema mínimo existencial tem como preencher as necessidades de uma determinada sociedade em uma data época. “[...] Nesse sentido, é possível falar-se até mesmo em mínimo existencial ecológico, no qual se inserem prestações básicas como o direito ao saneamento básico e à água potável” (SARLET, 2010, p. 29-33).

Barcellos (2002) entende que o mínimo existencial está essencialmente ligado à dignidade da pessoa humana e ao aspecto sociocultural da sociedade, não podendo ser visualizado como um direito autônomo, mas sim, um direito que representa um subconjunto de direitos sociais, econômicos e culturais que se destinam a possibilitar a plena realização do ser humano e que; por ter menor impacto financeiro, pode ser exigível judicialmente (BARCELLOS, 2002).

Apesar desse entendimento Espinoza (2017, p. 108) aponta o entendimento de Sarlet (2012) no sentido de que:

[...] os excessivos custos financeiros até mesmo para assegurar direitos sociais mínimos e a exigência de políticas públicas universais impõem a necessidade de, à luz do caso concreto, discutir uma série de questões tendo em vista a definir a prestação a ser concedida a determinado indivíduo pelo Judiciário. Nesse sentido, em relação à tutela judicial do direito à saúde, Sarlet aponta um conjunto de condicionamentos que deveriam orientar e limitar a atuação do judiciário, tais como: inexistência de tratamento alternativo eficiente, indispensabilidade do tratamento, proteção às pessoas efetivamente carentes de recursos, preferência em tutelas de urgência, eficiência e segurança do tratamento pleiteado, vedação de autorização de tratamentos experimentais, inexistência de obrigação genérica ao fornecimento de todo medicamento ou tratamento novo etc. [...]. Todas essas condicionantes parecem, portanto, indicar que o mínimo existencial a ser protegido concretamente só pode ser determinado após uma ponderação com demais bens, direitos e princípios envolvidos" (SARLET, 2012, 2013 apud ESPINOZA, 2017, p. 108).

Nesse sentido, a proteção ao mínimo existencial pelo Estado, através dos três poderes, deve ser projetada após uma ponderação de bens, direitos e princípios que são necessários à sociedade tendo em vista o princípio da dignidade da pessoa humana e a proteção à liberdade. 
Ademais, a dignidade da pessoa humana pode ser protegida em maior e menor grau pelo Estado, podendo, por omissão ou ação, gerar determinadas situações de flagrante indignidade o que implicaria um desrespeito ao mínimo existencial, já que este é o núcleo essencial da dignidade humana (BARCELLOS, 2011).

\section{Mínimo existencial, sujeitos e justiça}

A relação entre o mínimo existencial, direitos sociais e direitos fundamentais são de suma importância para a efetividade dos direitos sociais mínimos tendo em vista que, representam um avanço e uma garantia ao desenvolvimento do ser humano a uma vida digna. Ricardo Lobo Torres (1989, p.30) leciona:

\footnotetext{
Sem o mínimo necessário à existência cessa a possibilidade de sobrevivência do homem e desaparecem as condições iniciais da liberdade. A dignidade humana e as condições materiais da existência não podem retroceder aquém de um mínimo, do qual nem os prisioneiros, os doentes mentais e os indigentes podem ser privados.
}

O tema acerca do conteúdo do direito ao mínimo existencial é complexo, pois o entendimento sobre quais são as necessidades básicas varia nas diferentes sociedades existentes no mundo. Variações socioculturais significativas podem indicar que, o que é essencial a uma vida digna para uma sociedade, pode não ser para a outra dependendo então, da concepção de dignidade que cada sociedade tem.

A existência de necessidades materiais advindas da própria necessidade humana como alimentação, água, moradia e saúde são entendidas como necessidades universais e estão sujeitas a variações culturais. Mas, a delimitação do conceito de necessidade abrange também, as aceitas na comunidade em geral como aquelas derivadas de cada indivíduo em concreto tendo em vista que, as necessidades básicas variam conforme diferentes perspectivas podendo, dessa forma, "uma determinada prestação integrar o mínimo existencial para uma pessoa e não para outra" (SARMENTO, 2019, p. 215).

$\mathrm{Na}$ doutrina há várias tentativas para definir os direitos e as prestações que compõem o mínimo existencial. Há autores que apontam o mínimo existencial dentro do direito fundamental como núcleo essencial dos direitos sociais e, internacionalmente, o direcionamento da definição do conceito de mínimo existencial está sendo voltado aos direitos sociais. O Comitê de Direitos Econômicos, Sociais e Culturais da ONU, tem sido um dos influenciadores nesse sentido, apontou no seu Comentário-Geral no 3, de 1990, o dever 
dos Estados de garantirem imediatamente o minimum core dos direitos sociais previstos no Pacto Internacional dos Direitos Econômicos, Sociais e Culturais (SARMENTO, 2019, p. 217).

Entretanto, há autores que possuem outra linha de pensamento, como Sarlet, Figueiredo e Sarmento, no sentido de que o mínimo existencial e os direitos sociais até possuem "pontos importantes de contato, mas não se confundem" (SARMENTO, 2019, p. 217).

\begin{abstract}
Em primeiro lugar, porque nem todos os direitos sociais constitucionalmente garantidos se voltam à garantia de condições materiais básicas sem as quais não há vida digna. Veja-se, por exemplo, o direito ao $13^{\circ}$ salário, que, conquanto positivado na Constituição como direito social (art. $7^{\circ}$, VIII, CF) não guarda qualquer relação com as condições básicas para a vida com dignidade. Ademais, há prestações ligadas ao mínimo existencial que não foram contempladas em qualquer dos demais direitos positivados pela Constituição, não estando, portanto, garantidas pelos respectivos núcleos essenciais - e.g., direito ao vestuário adequado, mesmo onde o clima não torne o uso da roupa essencial para a proteção da saúde e da vida (SARMENTO, 2019, p. 217-218).
\end{abstract}

Independentemente de qualquer condição, o mínimo existencial possui caráter universal e tem por titular qualquer pessoa natural, não importando se preso, estrangeiro, idoso ou deficiente mas, dentre os titulares do direito ao mínimo existencial não se enquadram as pessoas jurídicas pois, "não são fins em si mesmas, não possuindo dignidade intrínseca, diferentemente das pessoas naturais" (SARMENTO, 2019, p. 213).

Assim, as necessidades básicas dos titulares do direito ao mínimo existencial variam dentro do contexto amplo sociocultural (necessidades universais) e da individualização da necessidade (necessidade de cada pessoa em concreto) de modo a conceber que a necessidade básica fique sujeita a várias interpretações e leituras. $\mathrm{O}$ atendimento às necessidades básicas, sem se desvincular da proteção à dignidade da pessoa humana, deve ter como escopo a ideia de justiça.

Daniel Sarmento (2019, p. 207) indica a correlação entre mínimo existencial, necessidades básicas e justiça cujo “atendimento às necessidades materiais básicas de pessoas que não possuem condições de fazê-lo por si próprias é o componente central da justiça, que justifica a sua proteção jurídica, inclusive no plano constitucional” indicando que, nem todas as justificativas à proteção ao mínimo existencial são instrumentais. $\mathrm{Na}$ perspectiva do autor o fundamento do mínimo existencial não estaria ligado à garantia da liberdade, mas sim ao atendimento às necessidades humanas onde, a liberdade seria apenas 
mais uma necessidade humana.

Para Tungendhat (2000 apud Sarmento, 2019, p. 207) a questão de a liberdade estar ligada ao mínimo existencial, deve ser entendida sob o "viés ideológico, partindo de premissas, equivocadas, que foram articuladas pelo contratualismo, que erigiu princípios supostamente universais a partir dos interesses dos indivíduos mais fortes”.

No interior da discussão jurídico-constitucional sobre direitos humanos ou fundamentais o conceito de liberdade exerce tradicionalmente o papel fundamental. A ideologia que estava atrás disso era que o ser humano 'na condição natural' sem Estado - seria em princípio livre; com a fundação de um Estado ele lhe deu parte de sua liberdade; a tarefa do Estado legítimo consiste em assegurar reciprocamente a liberdade dos indivíduos, conquanto que ela não prejudique a liberdade dos outros. (...) A orientação unilateral a partir da liberdade é, contudo, falsa até para a tradição liberal, porque sobretudo o direito à vida e à integridade física não é um direito de liberdade. Além disso, a ideia de uma condição natural é visto do ponto de vista moral, um mito ruim, porque ela parte exclusivamente dos adultos que têm condições de providenciar por si mesmos (...). Mas, fundamental para a pergunta pelos direitos que a gente tem somente pode ser o conceito da necessidade (ou interesse). O lugar da liberdade ficaria no ar se ela não fosse uma das necessidades fundamentais do indivíduo a ser reconhecida moralmente, da mesma forma que a necessidade da integridade física, mas também, p. ex., como a necessidade de ajuda, e de educação na fase da infância (...) bem como a necessidade da participação política (TUGENDHAT, 2000, p. 385-386 apud SARMENTO, 2019, p. 207-108).

$\mathrm{O}$ argumento acima orienta à necessidade de proteção aos indivíduos mais vulneráveis (incapacitados para o exercício da autonomia privada ou pública como crianças e pessoas com deficiência mental), ou seja, proteção aos indivíduos não pela ausência de condições materiais, mas por características de vulnerabilidade próprias. Assim, percebe-se que a ideia de justiça é ampla e deve permear as vulnerabilidades da sociedade.

Todos esses apontamentos acerca do mínimo existencial demonstram a necessidade de que se ponderar todos os bens, direitos e princípios envolvidos para que o mínimo existencial seja protegido concretamente.

\section{Considerações finais}

A garantia do direito ao mínimo existencial, como um direito fundamental quando não positivado ao texto constitucional, traz alguns enfrentamentos ao poder público tendo em vista, a necessidade de viabilizá-los ao longo do tempo para que o ser humano tenha uma vida digna que acompanhe a evolução da sociedade.

Assim, diante das necessidades humanas ilimitadas frente à recursos financeiros 
escassos, o Estado é incumbido a encontrar o melhor modo de gerenciar a aplicação dos recursos a fim de que sejam supridas as necessidades materiais mínimas ao desenvolvimento humano, correlacionando recursos e metas sociais, sem deixar de garantir o mínimo existencial.

No Brasil, a Constituição Federal de 1988 deu um passo importante ao trazer a positivação dos direitos sociais e a consagração do princípio da dignidade da pessoa humana como fundamento do Estado Democrático de Direito mas, apesar de o texto constitucional não trazer uma consagração expressa do direito ao mínimo existencial, muito se evoluiu na conquista dos direitos fundamentais sociais brasileiros. Contudo, ainda, muito se tem a evoluir.

Os questionamentos em torno do mínimo existencial estão intimamente ligados à dignidade da pessoa humana e a ideia de justiça social onde, alguns doutrinadores o consideram como um direito absoluto que deve ser garantido pelo Estado. Os direitos fundamentais sociais quando assegurados, para que a pessoa se desenvolva livremente, têm uma importância existencial para o indivíduo como ser formador da sociedade e, como pessoa respeitada dignamente pelo Estado.

A efetiva garantia ao mínimo existencial realizada através de políticas públicas pelo Estado, deve almejar a realização da justiça social, porém dentro dos limites orçamentários e, sempre protegendo dignidade da pessoa humana. Contudo, quando não houver a devida proteção ao direito, o conteúdo das políticas públicas pode vir a ser, eventualmente, exigido judicialmente, quando for insatisfatório ao ser humano o preenchimento das necessidades mínimas pelo Estado. Em sociedades periféricas, com grandes desnivelamentos sociais, o enfrentamento do tema ganha ainda mais densidade, devido a influência dos fatores multiculturais e econômicos.

O reconhecimento definitivo do direito ao mínimo existencial com delimitação conceitual, com fundamentação jurídica definida, se princípio ou regra e, ainda, sobre quais são as prestações mínimas e quais os indivíduos, que necessitam dessa prestação continua em debate entre os estudiosos. Contudo, dentre os apontamentos aqui apresentados, verifica-se que o direito ao mínimo existencial como um direito fundamental, pode ser exigido judicialmente e, deve permear a ideia de justiça através da ponderação de bens, direitos e princípios.

Independentemente de quais fundamentos possam ser atrelados ao conceito, a 
efetivação dos direitos fundamentais sociais deve ser destacada por meio do sopesamento entre os princípios, ponderando princípios materiais e fundamentais envolvidos com o princípio da liberdade fática e o princípio da separação dos poderes.

Ademais, o mínimo existencial está essencialmente ligado à dignidade da pessoa humana e ao aspecto sociocultural da sociedade, não podendo ser, portanto, visualizado como um direito autônomo, mas sim, um direito que representa um subconjunto de direitos sociais, econômicos e culturais que se destinam a possibilitar a plena realização do ser humano e que; por ter menor impacto financeiro, pode ser exigível judicialmente. Logo, o mínimo existencial é o núcleo essencial da dignidade humana.

\section{Referências}

ALEXY, Robert. Teoria dos direitos fundamentais. Tradução Virgílio Afonso da Silva.5. ed. São Paulo: Malheiros, 2008.

BARCELLOS, Ana Paula de. A eficácia jurídica dos princípios constitucionais. Rio de Janeiro: Renovar, 2002.

BARCELLOS, Ana Paula de. O mínimo existencial e algumas fundamentações: John Rawls, Michael Walzer e Robert Alexy. In: Ricardo Lobo Torres (Org.).

A Legitimação dos direitos humanos. Rio de Janeiro: Renovar, 2002.

BARCELLOS, Ana Paula de. O direito a prestações de saúde: complexidades, mínimo existencial e o valor das abordagens coletiva e abstrata. In: Cláudio Pereira de Souza Neto; Daniel Sarmento (Coords.). Direitos sociais: fundamentos, judicialização e direitos sociais em espécie. Rio de Janeiro: Lumen Juris, 2008.

BARCELLOS, Ana Paula de. A eficácia jurídica dos princípios constitucionais: o princípio da dignidade da pessoa humana. 3. ed. Rio de Janeiro: Renovar, 2011.

BARROSO, Luís Roberto. A doutrina brasileira da efetividade. In: Temas de Direito Constitucional. Rio de Janeiro: Renovar, 2005.

BARROSO, Luís Roberto. O direito constitucional e a efetividade das suas normas. 8. ed. Rio de Janeiro: Renovar, 2006.

BITTENCOURT NETO, Eurico. O direito ao mínimo para uma existência digna. Porto Alegre: Livraria do Advogado, 2010.

BOBBIO, Norberto. A Era dos Direitos. Tradução: Carlos Nelson Coutinho. Editora Campus. Rio de Janeiro, 1992. 
COSTA, Ruth Barros Pettersen da. A efetividade do mínimo existencial como função essencial do Estado. Anais do XVII Congresso Nacional do CONPEDI. Brasília. nov. 2008. Disponível em:

http://www.publicadireito.com.br/conpedi/manaus/arquivos/anais/brasilia/14_707.pdf. Acesso em: 03 de nov. de 2019.

ESPOLADOR, Rita de C. Resquetti; FURLAN, Alessandra Cristina. Algumas considerações sobre o mínimo existencial à luz da dignidade da pessoa humana. Revista direito privado da UEL. v. 1, n. 3. Disponível em:

http://www.uel.br/revistas/direitoprivado/artigos/Rita_e_Alessandra_MinimoExistencial.pdf. Acesso em: 03 de nov. de 2019.

ESPINOZA, Danielle Sales Echaiz. A doutrina do mínimo existencial. Revista Interfaces Científica - Humanas e Sociais. Aracajú. v. 6, n.1, p. 101 - 112. jun. 2017. Disponível em: http://www.mpsp.mp.br/portal/page/portal/documentacao_e_divulgacao/doc_biblioteca/ bibli_servicos_produtos/bibli_informativo/bibli_inf_2006/Interf-Hum_v.6_n.1.10.pdf. Acesso em: 10 dez. 2019.

GRAU, Eros Roberto. Planejamento econômico e regra jurídica. São Paulo: Revista dos Tribunais, 1978.

HACHEM, Daniel Wunder. A utilização do mínimo existencial como critério de exigibilidade dos direitos fundamentais econômicos e sociais: reflexões críticas.

Revista de direito da UNISC. n. 40, agosto/out., 2013. Disponível em: https://online.unisc.br/seer/index.php/direito/article/view/3594. Acesso em: out. 2019.

KRELL, Andréas. Direitos Sociais e controle judicial no Brasil e na Alemanha: os (des)caminhos de um direito constitucional "comparado". Porto Alegre: Sergio Antônio Fabris Editor, 2002.

KRELL, Andréas. Discricionariedade administrativa e protesão ambiental: o controle dos Conceitos Jurídicos Indeterminados e a Competência dos Órgãos Ambientais. Um Estudo Comparativo. Porto Alegre: Editora do Advogado, 2004.

MACHADO, Edinilson Donisete; HERRERA, Luiz Henrique Martim. O mínimo existencial e a reserva do possível: ponderação hermenêutica reveladora de um substancialismo mitigado. Anais do XIX Encontro Nacional do CONPEDI. Fortaleza. jun. 2010. Disponível em: http://www.publicadireito.com.br/conpedi/manaus/arquivos/anais/fortaleza/3480.pdf. Acesso em: nov. 2010.

MIRANDA, Pontes de. Teoria do Estado e da Constituição. Rio de Janeiro: Forense, 2002.

PEREIRA, Potyara A. Necessidades humanas: subsídios à crítica dos mínimos sociais. 6. ed. São Paulo: Cortez Editora, 2000.

PIMENTA, Paulo Roberto Lyrio. As normas constitucionais programáticas e a reserva do 
possível. Revista de Informação Legislativa. Brasília, 2012, ano 49, n. 193. jan. / mar. Disponível em:

https://www2.senado.leg.br/bdsf/bitstream/handle/id/496925/RIL193.pdf?sequence=1\# page $=8$. Acesso em: $10 \mathrm{dez}$ de 2019 .

SCAFF, Fernando Facury; MAUÉS, Antonio G. Moreira. Justiça Constitucional e Tributação. São Paulo: Dialética, 2005.

SCAFF, Fernando Facury. Reserva do possível, mínimo existencial e direitos humanos.

Revista Argumentum. Marília, 2006, v. 6. Disponível em:

http://ojs.unimar.br/index.php/revistaargumentum/article/view/731. Acesso em $12 \mathrm{de}$ dez. 2019.

SARLET, Ingo Wolfgang. Os Direitos Fundamentais Sociais na Constituição de 1988. Revista Diálogo Jurídico, Salvador, v. 1, n. 1, 2001. Disponível em:

www.direitopublico.com.br. Acesso em: nov. 2019.

SARLET, Ingo. A eficácia dos direitos fundamentais. 2. ed. Porto Alegre: Livraria do Advogado, 2001.

SARLET, Ingo Wolfgang. Dignidade (da pessoa) humana, mínimo existencial e justiça constitucional: algumas aproximações e alguns desafios. Revista do CEJUR/TJSC.

2001. v. 1. n. 1. Disponível em: https://revistadocejur.tjsc.jus.br/cejur/article/view/24. Acesso em: nov. 2019.

SARLET, Ingo Wolfgang. Os direitos sociais como direitos fundamentais: contributo para um balanço aos vinte anos da Constituição Federal de 1988. Disponível em: http://www.stf.jus.br/arquivo/cms/processoAudienciaPublicaSaude/anexo/artigo_Ingo_ DF_sociais_PETROPOLIS_final_01_09_08.pdf. Acesso em: nov. 2019.

SARLET, Ingo Wolfgang; FIGUEIREDO, Mariana Filchtiner. Reserva do possível, mínimo existencial e direito à saúde: algumas aproximações. In: Direitos Fundamentais e Justiça, Porto Alegre, ano 1, n. 1, p. 171-231, out./dez., 2007.

SARLET, Ingo Wolfgang. O direito ao mínimo existencial não é uma mera garantia de sobrevivência. 2015. Disponível em: https://www.conjur.com.br/2015-mai-08/direitosfundamentais-assim-chamado-direito-minimo-existencial. Acesso em: out. 2019.

SARLET, Ingo Wolfgang; ZOCKUN, Carolina Zancaner. Notas sobre o mínimo existencial e sua interpretação pelo STF no âmbito do controle judicial das políticas públicas com base nos direitos sociais. Revista de Investigações

Constitucionais.Curitiba, v.3, n. 2, aug. 2016. Disponível em: http://www.scielo.br/scielo.php?script=sci_arttext\&pid=S2359-56392016000200115. Acesso em: out. 2019.

SARLET, Ingo Wolfgang. Algumas aproximações entre direitos sociais e mínimo existencial. 2017. Disponível em: https://www.conjur.com.br/2017-set-01/direitosfundamentais-algumas-aproximacoes-entre-direitos-sociais-minimo-existencial. 
Acesso em: out. 2019.

SARLET, Ingo Wolfgang; FIGUEIREDO, Mariana Filchtiner. Reserva do possível, mínimo existencial e direito à saúde: algumas aproximações. In: SARLET, Ingo Wolfgang; TIMM, Luciano Benetti (Orgs.). Direitos fundamentais: orçamento e reserva do possível. Porto Alegre: Livr. do Advogado, 2013. p. 13-50.

SARLET, Ingo Wolfgang.Reserva do possível, mínimo existencial e direito à saúde: algumas aproximações. Revista de Doutrina da $4^{\mathrm{a}}$ Região, Porto Alegre, n. 24, jul. 2008. Disponível em: <http://www.revistadoutrina.trf4.jus.br/artigos/edicao024/ingo_mariana.html>. Acesso em: nov. 2019.

SARMENTO, Daniel. A dignidade da pessoa humana: conteúdo, trajetória e metodologia. 2. ed. Belo Horizonte: Fórum, 2019.

SEN, Amarthya. Desenvolvimento como Liberdade. 3. ed. São Paulo: Companhia das Letras, 2000.

TOLEDO, Cláudia. Mínimo existencial: A construção de um conceito e seu tratamento pela jurisprudência constitucional brasileira e alemã. PIDCC. Aracajú. Ano VI, v. 11, n.1, p. 102 - 119. fev 2017. Disponível em: http://www.pidcc.com.br/en/special- issues/2-

uncategorised/262-minimo-existencial-a-construcao-de-um-conceito-e-seu- tratamento-pelajurisprudencia-constitucional-brasileira-e-alema. Acesso em: out.2019.

TORRES, Ricardo Lobo.O mínimo existencial e os direitos fundamentais. Revista de Direito Administrativo. Rio de Janeiro.1989. n. 177, p. 29 - 49. jul./set. Disponível em: http://bibliotecadigital.fgv.br/ojs/index.php/rda/article/download/46113/44271. Acesso em: set. 2019.

TORRES, Ricardo Lobo. A metamorfose dos direitos sociais em mínimo existencial. In. SARLET, Ingo Wolfgan (Org.) Direitos fundamentais sociais: estudos de direito constitucional, internacional e comparado. Rio de Janeiro: Renovar, 2003.

TREVISAN, Leonardo Simchen. Os direitos fundamentais sociais na Teoria de Robert Alexy. Cadernos do Programa de Pós-Graduação em Direito - PPGDir./UFRGS. 2015. v. 10, n. 1. Disponível em: https://seer.ufrgs.br/ppgdir/article/view/54583. Acesso em: nov. 2019.

VOLPE, Karina Rocha Martins. Efetivação dos direitos sociais na ótica do mínimo existencial e da reserva do possível. Revista Brasileira de Planejamento e Orçamento. 2012. v.2, n. 1, p. 48 -67. Disponível em:

https://www.assecor.org.br/files/6213/5886/3066/rbpo_efetivacao_direitos_sociais.pdf. Acesso em: 04 dez. 2019. 